\title{
Historia y género
}

El conocimiento científico, acumulado a lo largo de los siglos, sin tener en cuenta un hecho obvio pero ignorado por el discurso académico hasta la época actual: que hombres y mujeres son sujetos y objetos de la historia.

Utilizando las metodologías más actuales de las Ciencias Sociales y en especial la concepción de la "multitud" como elemento axial de análisis histórico, ha sido perceptible detectar la presencia de esos seres históricos pocos visibles: negros, campesinos, indígenas, mujeres. Es necesario rescalar los planteamientos que la sociedad patriarcal estrucluró hace $\mathrm{V}$ siglos para las sociedades sedentarias-agrícolas del Próximo Oriente y que pese a los cambios generados en las formas políticas y sociales a lo largo del tiempo, se paralizaron y fosilizaron en lo concerniente a las relaciones entre hombres y mujeres y a la supuesta superioridad intelectual y moral de estos sobre aquellas.

tLa categoría "género" analiza las relaciones sociales entre los hombres y las mujeres como elementos constitutivos del discurrir histórico. Interpela, además, a las ciencias sociales en la medida que no han producido un conocimiento sobre las mujeres, más de la mitad de la humanidad, y han mantenido construcciones culturales peyorativas e incorrectas. Se parte del conceplo de género entendido como una construcción cultural y social que se articula a partir de las definiciones normativas de lo masculino y femenino, la creación de una identidad subjetiva y las relaciones de poder lanto entre hombres y mujeres como en la sociedad en su conjunto. Esta perspectiva analítica supone una visión alternativa a la creación de identidades culturales prefijadas en función del sexo, demanda un replantamiento global de los ejes interpretativos de la historia y libera a los hombres y a las mujeres de rigidos planteamientos que les hurtaban su propia identidad y les concedian personalidades estereotipadas.

A lo largo de un mes y en unidades didáclicas de dos horas y media, tres días a la semana, se han ido analizando textos jurídicos, morales, literarios o científi$\cos$, en donde las funciones prefijadas de género se establecían axiomaticamente 
desde planteamientos basado en aprioristicas concepciones sectarias.

Se han analizado las diferencias sexo género, a la luz de la confusión naturaleza-cultura. El trabajo en la sociedad patriarcal, la fija estructuración de espacios públicos o privados atribuibles en relación al sexo, la diferencia otorgada a la educación e instrucción entre los hombres y las mujeres. . . .Los diversos textos históricos utilizados desde épocas antiguas hasta la contemporánea han facilitado el análisis de unas ideas que, pese a su no equidad y concepciones erróneas, han permanecido demasiado tiempo como elementos constitutivos del imaginario colectivo. La crítica solitaria de algunas mujeres primero, la acción de grupos de mujeres organizadas junto a la imupción femenina en la educación y el trabajo laboral extradoméstico, han posibilitado el movimiento de crítica y de revisión conceptual que urge continuar desarrollando. Finalmente analizar el feminismo como una teoría política que lucha contra la desigualdad ha sido un elemento significativo para el análisis del curso y para hacer una revisión del discurso científico acumulado acríticamente a lo largo de la historia.

\section{Historia y Género}

Uno de los hechos más revolucionarios y significativos del siglo $\mathrm{XX}$, es la presencia femenina con voz propia en la esfera pública y privada. Tras largos siglos de silencio e infravalorización de su significado histórico, la incorporación masiva de mujeres al trabajo asalariado y a la educación ha desencadenado un hecho de enorme magnitud y trascendencia social: El cuestionamiento general de los "universales", tenidos como tales por la sociedad patriarcal, y la urgencia de revisar el conocimiento científico y las práclicas sociales con categorías menos sectarias, en donde hombres y mujeres sean sujelos y objelos de la historia.

El desartollo de las ciencias sociales y de nuevos planteamiento metodológicos que tienen en cuenta la presencia como sujetos históricos que tienen en cuenta la presencia como sujelos históricos de pleno derecho, de la "multitud" de seres humanos, en feliz frase de Rudéz, tradicionalmente excluidos, han permitido cambios significativos. Durante la década de los años 70' fueron analizándose colectivos humanos excluidos sistemáticamente del discurso académico: campesinos, artesanos, obreros. . .; más tarde fueron incorporándose las elnias ignoradas, finalmente el colectivo más numeroso de la humanidad: Las mujeres, que habían permanecido "invisibles" al conocimiento científico. Comenzaba así a ser factible la posibilidad de realizar trabajos que no ignorasen el hecho de que hombres y mujeres son sujetos y objetos del análisis histórico.

Pero tras esta evidencia -a la que se ha llegado demasiado tarde pese a su obviedad-, todo un amplio conjunto de planteamienlos e ideas preconcebidas comenzaban a no ser fácilmente mantenibles. La polaridad en la que se ha desa- 
rrollado el discurrir de la vida de hombres y mujeres, marcados por unos papeles que a unos y a otras se prefijaban de antemano y a los que no se podía contravenir, ha roto a lo largo de la historia mucha creatividad y libertad y ha generado situaciones dolorosas a muchos seres humanos, sin distinción de sexo. Precisamente de la distinción entre sexo y género pretendo hablar en este artículo.

Durante muchos años, casi 5,000, se ha venido manteniendo en la sociedad un determinismo biológico que no se sostiene desde el más mínimo presupuesto científico. Afortunadamente, al menos a nivel teórico hoy parece superada la ideas de que hombres y mujeres no eran depositarios de una misma ciudadanía política. Sin embargo subsisten todavía muchas construcciones sociales y culturales con fundamentos ambiguos e inestables que pesan sobre la vida de unos y de otras.

La categoría Género, utilizada en este trabajo, permite analizar las relaciones sociales entre hombres y mujeres como elementos constitutivos del discurrir histórico, siendo consciente de su diferente identidad más no aceptando su desigualdad. Interpela, por tanto, a las ciencias sociales en la medida en que no han producido un saber sobre las mujeres, más de la milad de los seres humanos, puesto que no llegaron nunca a deslacarlas como problema teórico.

Se entiende por género una construcción cultural y social que se articula a partir de las definiciones normativas de lo masculino y de lo femenino, la creación de una identidad subjetiva y las relaciones de poder tanto entre hombre y mujeres como en la sociedad en su conjunto?.

El análisis de género permite detectar la especificidad de la experiencia femenina y, a la vez, establecer las pautas de su integración en los procesos históricos. Del mismo modo que las categorías de clase social y raza han permitido un avance significativo en nuestra percepción de la realidad histórica, la categoría analítica género permite un cambio de paradigma histórico que integra a las mujeres como agentes y sujelos de transformación social. Libera además a los hombres de rígidos planteamientos nomativos que les hurtaban de su sensibilidad y les conferían una personalidad estereolipada. Esta perspectiva analítica supone una visión alternativa a la creación de identidades culturales prefijadas en función del sexo e implica un replanteamiento global de los grandes ejes interpretativos de la historia.

Desde la perspectiva de género, por ejemplo, es lícito proceder a un cuestionamiento de ideas tenidas universalmente como fundamentales, como el concepto de progreso, por ejemplo, como eje interpretativo de la evolución de la historia occidental. Así en su vertiente de progreso político no se puede hablar de progreso universal cuando los derechos políticos no incluyen a colectivos sociales marginados como el de las mujeres, negros, indígenas, elc. Difícilmente se puede hablar de democracia radical en Grecia, cuando las mujeres ciudadanas 
no podian participar en ninguno de los centros de decisión y cuando la ciudadanía política solo era disfrutada por la clase alta de la sociedad. Del mismo modo, en el desarrollo de las revoluciones liberales y democrálicas de la sociedad Del mismo modo, en el desartollo de las revoluciones liberales y democráticas de la sociedad contemporánea, es necesario revisar el concepto de igualdad y de ciudadanía de estos sistemas. La revolución liberal, por ejemplo, privilegiaba a los varones propietarios del resto de la sociedad y solo a ellos les concedía esa ciudadanía.

La categoría de género rompe también la polaridad público-privado, exterior e interior, como espacios políticos y materiales fijos y atribuibles por su supuesta naturaleza, a varones y mujeres. La aportación de los nuevos estudios ha puesto de relieve la historicidad de la conceptualización de lo público y privado en las respectivas sociedades y las modalidades específicas que han aportado. Ello permite analizar a las mujeres en dominios públicos y a los varones en dominios privados. De este modo se contempla la interacción entre lo público y lo privado como clave histórica y revaloriza estos ámbitos en su significado histórico.

La discusión en tomo al debate naturaleza-cultura representa otro campo de reflexión donde el género ha introducido una perspectiva renovadora a la concepción histórica tradicional. Desde la antigüedad la proyección social de la mujer ha estado mediatizada por su propia biología y sus funciones sociales y políticas han estado determinadas por la misma, mientras que los varones han sido definidos por su capacidad de razonamiento y por su creatividad histórica a partir del "Loaos". La obra de Rousseau," por ejemplo es uno de los ejemplos más paradigmáticos. En su "Emilio" y su "Sofía", categoriza sobre las identidades masculinas y femeninas dentro de una plena concepción patriarcal y sin el menor rubor intelectual. Toda una literatura moral dentro de la religión católica incidía sobre la incapacidad inteleclual y moral de las mujeres y la necesidad del tutelaje masculino. Los ordenamientos jurídicos no hacían sino reforzar y obligar a la obligada sumisión femenina.

Este planteamiento ha estado en la base de la justificación del reparto de funciones de género a lo largo de la historia. La historiografía tradicional ha reproducido este esquema justificativo para explicar las funciones de hombre y mujer en la sociedad. La historia de las mujeres al cucstionar este presupuesto, ha planteado que la definición de estos papeles están determinadas por construcciones históricas de índole socio-cultural y no biológicas, Relacionado con este debate en tomo a la naturaleza y a la cultura habría que señalar el de la igualdad-diferencia de las mujeres en la historia, y por tanto de la urgencia de incorporar al análisis histórico el valor de la experiencia de ambos sexos.

Otro elemento a destacar es la propia evolución de la historiografía feminista a partir del debate en torno a la mujer como víclima o prolagonista de la histo- 
ria. Se parte de la base de considerar el feminismo como una teoría política que desenmascara las desigualdades de la sociedad. Su eje interpretativo inicial, hace dos décadas, fue la victimización histórica de las mujeres: y tal como había planteado Simone de Bouvoiur las mujeres no tenían proyecto histórico propio. No obstante, el desarrollo de la investigación histórica ha permitido matizar y replantear esos supuestos. Hoy no se pretende situar a las mujeres como víclimas o heroicas protagonislas, sino establecer su trayectoria histórica específica. Así se trata de estudiar a hombres y a mujeres y la relación entre ambos pero sin asignarles a priori espacios, valores, comportamientos y objetivos.

Todo ello ha permitido incorporar nuevos temas al análisis histórico, que enriquecen nuestro conocimiento. El estudio de facetas tan importantes como los sentimientos, la sexualidad, la maternidad, los ciclos de vida, las relaciones personales, la vida cotidiana... ha significado una revisión de viejos presupuestos en torno al poder, al trabajo la cultura, la producción o la democracia. En las diferentes épocas históricas se destacan una serie de pautas que definen la trayectoria de los hombres y de las mujeres en esas coyunturas.

Otra cuestión capital es la construcción cultural de las funciones de género. Se ha partido de la historicidad de dicha construcción y un somero análisis de textos legales, literarios o religiosos refleja claramente como la ideología patriarcal y los mecanismos particulares científicos, filosóficos y morales han contribuido a definir el discurso de género en cada época histórica. A través del análisis documental se percibe la diferente incidencia de cada uno de estos elementos en las sociedades analizadas. Es evidente que el peso de la religión en la afirmación de las funciones de género ha sido decisiva a lo largo de la historia y de forma particular en el período contra reformista posterior a 1,565 , fecha del concilio de Trento. La creciente laicización de la sociedad desde la ilustración ha concedido mayor importancia a otros discursos médico-científico, más concordantes con ese modelo de sociedad. También se puede destacar como en todas las épocas históricas el aparato jurídico ha funcionado como mecanismo de definición y garantía de reproducción de los papeles de género. Si en el derecho castellano, por ejemplo, los padres no permilían contraer matrimonio a sus hijos e hijas antes de los 25 años sin su consentimiento y bajo sanción punible de la justicia; esa situación significaba la dependencia absoluta de las mujeres respecto al cabeza de familia para contraer matrimonio, dada la obligatoriedad de poseer una dote para acceder a un matrimonio ventajoso.

La dote, en bienes muebles o inmuebles, la concedía el padre en virtud del estatus familiar y si no había una aceptación femenina a los deseos paternos, sus posibilidades de poseer una vida propia, a través del matrimonio, se cancelaban definitivamente. La Novísima Recopilación de Leyes de España e Indias de 1803 todavía reforzaba y mantenía esa dependencia respecto al cabeza de familia." Evidentemente los matrimonios clandestinos no eran frecuentes y las rela- 
ciones de amor no eran las que primaban en esas uniones matrimoniales. Una "doble vida", la del hogar, las de las relaciones afectivas y sexuales, se fue generando como consecuencia de estas situaciones. Si analizásemos el vigor de las sociedades solo por el contenido de felicidad alcanzada por sus habitantes, la conclusión sería clara: Un alto nivel de infelicidad y de situaciones afectivas complicadas presidió la vida de la mayoría de nuestros antepasados.

El análisis de género ha implicado también una revisión del concepto del poder. Aunque las mujeres no han accedido a los centros de poder formal hasta décadas recientes, sin embargo sería equivoco plantear que las mujeres no han ejercido fuertes influencias en múltiples ámbitos de acluación. Si bien es cierto que las mujeres no llegaron a formular, de forma colectiva, una área de poder hasta la época contemporánea, con el surgimiento de los movimientos feministas del siglo $\mathrm{XX}$, algunas mujeres individuales ejercieron cierto grado de poder tanto en los ámbitos públicos como privado. Fue importante, por ejemplo, la influencia de ricas propietarias romanas, de señoras feudales o de abadesas medievales. No menos importante fue el poder de mujeres arislocrálicas francesas o inglesas, ejercidos en sus salones, y abiertos a debates intelectuales y políticos durante los siglos XVII y XVIII. Asimismo cabe proceder, desde el análisis de género, a una relectura del significado de figuras políticas como Isabel de Castilla, Catalina de Rusia o Isabel I de Inglaterra. Por otra parte, ya que las mujeres han presentado un colectivo social inarticulado y marginado del poder formal, habría que reinterpretar el concepto de poder para abarcar horizontes nuevos sobre los poderes que pueden ejercer las mujeres sobre el control de su propio cuerpo, sobre la familia, sobre las relaciones de barrio o en la proyección colectiva de la comunidad.

En todas las épocas históricas se refleja la aportación constante del trabajo de las mujeres en el desarrollo de la sociedad.' Las mujeres siempre han trabajado, no obstante la interpretación del trabajo ha ocultado esa realidad histórica y ha convertido en invisible el trabajo de las mujeres. El análisis de género plantea por lo tanto, una reconsideración del valor económico y social del trabajo femenino junto al trabajo masculino, como la necesidad urgente de valorar como trabajo productivo al trabajo doméstico, mayoritariamente realizado por mujeres. La revalorización del ámbito privado en la historiografía aclual ha permitido explicar el significado para el desarrollo económico del trabajo, no remunerado, de las mujeres. Desde las claves de género se han podido comprender mejor las causas de las desvalorización del trabajo de las mujeres y su conceptualización histórica. Resulta estremecedor escuchar a muchas mujeres trabajadoras en sus casas, su propia apreciación de no trabajar; ejemplo significativo de como la asimilación de trabajo con trabajo asalariado, efectuada por la economía capitalista ha desenfocado palmariamente el concepto laboral.

La regulación laboral, a su vez, ha representado un mecanismo clave en la 
configuración del trabajo femenino: su canalización hacia determinados sectores de producción, su valoración económica y sus salidas profesionales. Así, la regulación y exclusión del trabajo de las mujeres en los gremios europeos, actuó para frenar la plena integración de las mujeres en la vida laboral, del mismo modo que en el siglo XX, la formulación laboral proteccionista, al mismo tiempo que estableció directrices de previsión social para las madres trabajadoras, delimitó sus ámbilos y condiciones laborales excluyentes. De este modo, en los distintos momentos históricos, el sistema legislativo patriarcal, discriminó laboral y salarialmente a las mujeres.

Otra de las aportaciones claves de la historia de las mujeres ha sido la revalorización de su presencia en el desarrollo histórico, a partir de su capacidad reproductiva. El tema de la maternidad y del control del cuerpo de las mujeres ha sido clave en la pervivencia y permanencia de la sociedad patriarcal, tan escasamente equitativa. Nos toca a las historiadoras y a los historiadores plantear los mecanismos específicos de control que se establecieron en las distintas épocas históricas - regulación de la prostitución, penalización del aborto, políticas pronatalistas, doble código de moral sexual, elc. El aborto, el infanticidio, el desarrollo de las técnicas anticonceptivas y el acceso a ellas son temas de gran interés para la comprensión de las pautas demográficas desarrolladas a lo largo de la humanidad y para el significado de la maternidad desde la antigüedad hasta nuestros dias.

Por último es necesario abordar los itinerarios masculinos y femeninos de cambio y continuidad. La pluralidad de estos itinerarios y los variados procesos de concienciación de hombres y de mujeres son evidentes. Destaca la intervención de estas en las diferentes modalidades de acción colectiva y de protesta social a lo largo de los siglos, aunque también cabe destacar su grado de intervención en ellos así como su grado de asunción de los papeles asignados para ellas. Las estràtegias de resistencia de las mujeres abarcaron tanto la defensa de su entorno familiar - participación en los motines de hambre, por ejemplo_ como el de la colectividad. Según el momento, la motivación que los llevara a la protesta o a la organización de movimientos sociales, podía derivar bien de la defensa de las necesidades básicas familiares o de planteamientos específicos de género así como elementos defensores de su clase o identidad.

Aunque la dinámica de resistencia y confrontación ${ }^{\sharp}$ de las mujeres en la sociedad ha funcionado a lo largo de la historia, es necesario plantear como las mismas mujeres han funcionado a partir de estrategias de complicidad y reproducción del sistema de género, definido sobre la autoridad suprema del varón. Sin duda una de las claves para la comprensión de su subordinación histórica, es la identificación de los mecanismos que las llevaron a asumir la aceptación de los mecanismos de control de género, así como la trasmisión de valores peyorativos y negativos respecto a mujeres. 
La resistencia femenina se ha expresado a partir de su concienciación como colectivo social específico en la sociedad contemporánea que ha llevado desde finales del siglo XIX a las primeras formulaciones del feminismo occidental. EI proceso de revisión epistemológico que el análisis de género produce, así como la crítica de los supuestos cienlíficos tomados como universales, por el conjunto de la academia, no ha hecho sino comenzar.

\section{Notas:}

1. Profesora de la Universidad Aulónoma de Madrid. La aulora agradece a Zoila de Innocenti la oportunidad que le otorgó de cnseñar un curso en la UCA, donde se desarrollaron estas ideas.

2. Las Multirud en la historia, Madrid 1983.

3. J. Scott. El Género una categoría para el análisis histórico. En Historia y género de J. Amelang y M. Nash. Valencia 1990.

J. Bock: La historia de las mujeres y la historia del género; Aspeclos de un debate internacional. En historia social No. 9. Valencia 1991.

4. J. J. Rousscau. "Emilio". Madrid 1994.

5. P. Burke, Formas de hacer historia, Madrid 1993.

Perrot J . Duby: Historia de las mujeres. 5 vol. Madrid 1992-1993.

6. Novísima Recopilación de Leyes de España e Indias. Madrid 3 vol. 1803.

VVAA. Historia de la familia. Historia 16, Madrid 1987.

VVAA. Historia de las mujeres. Historia 16, Madrid 1989.

7. J. Matilla y M. Ortega: El trabajo de las mujeres: Siglos XVI al XX, Madrid, Universidad Autónoma dc Madrid, 1995.

8. Ortega López, M. Las mujeres de Madrid, agentes de cambio sociales. Universidad Aulónoma de Madrid. 1995.

Maqucira V. y Ortcga M. Mujeres y hombres en la formación del pensamiento occidental, Madrid, Universidad Autónoma de Madrid. 1989.

VVAA. Texios para la historia de las mujeres en España. Madrid Ed. Cátedra. 1994. 